\title{
电梯轿层门在层站非平层区的安全保护
}

\author{
杨飞 \\ 西继迅达(许昌)电梯有限公司 \\ DOI:10.18686/bd.v2i2.1245
}

[摘要] 电梯事故频发的警钟不断在身边敲响,尽快并寻找提升电梯安全性能的方法迫在眉睫。其中电梯轿门和层门处是 隐患存在的重要区域。本文从电梯自身设计、生产质量提升、相关部门监管、和电梯看护人员日常保养维护、消费者规范使 用五个方面对电梯轿层门在层站非平层区的安全防护措施进行表述, 以期为电梯安全事故的解决提供参考依据。

[关键词] 电梯轿层门;非平层区; 安全保护

随着城市范围的不断扩大, 高楼林立成为了都市生活 的典型景观, 其中电梯的存在和发展给人们的生活带来了 不可忽视的便利。人们对这种便利不断认知和依赖的过程 中, 也同时沉浸在它引起的一系列事故的恐惧和悲痛中无 法释怀。在追求人类文明的道路上,人民群众的人身和财产 安全受到不同程度的损害。在 2016 年的一年时间里,我国 总共出现 48 起电梯安全事故,造成的死亡人数达 41 人。其 中电梯轿门和层门处是隐患存在的重要区域。电梯轿层门
未精准的停留在层站平层区或突然启动等造成乘坐者坠人 电梯井的事故频发。造成事故发生的原因有很多, 其中电梯 自身设计问题、生产质量不合格、相关部门监管不够和电梯 看护人员日常保和检修不规范、消费者的不规范使用等都 可能造成事故。本文从以上五方面出发, 对电梯轿层门在层 站非平层区的安全防护措施进行表述。

\section{1 改进电梯自身设计}

电梯正常运行的标准主要是层门和轿门在规定的层站
成可用输出信号的一种传感装置。

\section{3 影响电梯安全性能的主要因素及其措施}

3.1 影响电梯安全性能的因素

3.1.1 检验检测机构人员的因素。为了查验电梯使用单 位与维护保养单位是否执行了相关的法律法规, 国家质监 总局核准了特种设备检验检测机构对新安装电梯实施监督 检验检测,对在用电梯实施一年一度的定期检验检测 (因特 殊原因可以提前检验检测)。由于电梯检验检测人员的素质 及教育水平不同, 可能会在电梯的检验检测中疏忽掉一些 安全问题,从而使电梯带病运行,给人们造成生命财产的损 失, 因此必须要加强检验检测人员的技术水平, 做到不漏检。

3.1 .2 日常使用和保养方面的因素。投人使用的电梯,不 仅要有使用单位的管理, 还要有维护保养单位的日常维护 保养, 这是电梯安全运行的关键因素, 如果使用单位不能很 好的管理, 维护保养单位不按照相关的法律法规进行维护 保养,将会导致电梯不能正常运行,故障频发,甚至会造成人 员伤亡。

3.2 保障电梯安全性能的措施。具体表现为:

3.2.1 严格检验检测人员的职责。电梯检验检测过程中, 最基本的是提高检验检测人员的素质及业务技术水平。《中 华人民共和国特种设备安全法》第五十一条规定: 特种设备 检验检测、检测机构的检验检测、检测人员应当经考核, 取 得检验检测、检测人员资格, 方可从事检验检测、检测工作。 这是提高电梯检验检测质量最基本的条件。只有检验检测 人员具有了一定的专业知识, 才能在检验检测中发现安全 隐患, 并及时督促维护保养人员整改, 排除电梯存在的安全
隐患, 从而提高电梯的安全性能。电梯检验检测人员在检验 检测过程中如果发现电梯存在严重事故隐患时, 应及时告 知相关单位, 并立即向负责特种设备安全监督管理的部门 报告。监督管理部门对检验检测结果进行抽查, 并责令使用 单位停止电梯运行, 杜绝电梯带病运行。

3.2.2 加强电梯的定期检验检测。TSGT7001-2009《电 梯监督检验与定期检验规则 - 曳引与强制驱动电梯》规定: 定期检验检测是对电梯生产和使用单位执行相关法规标准 规定、落实安全责任,开展为保证和自主确认电梯安全的相 关工作质量情况的查证性检验检测。定期检验检测提高了 电梯的安全性能,防止电梯带病运行, 避免安全事故的发生。

\section{4 结束语}

综上所述, 目前作为高层建筑物配备设施的电梯设备 被广泛出现在人们日常生活中, 给予人们生活上的便利, 然 而同时产生危害人们安全的隐患。高层建筑物对电梯控制 系统以及性能要求提高的同时, 更要求其有更先进、可靠的 安全防护系统, 因此对电梯失速下降箱内救生装置进行分 析非常重要。

\section{参考文献:}

[1]杨娜.浅谈电梯安全系统与电梯常见事故[J]. 科技 创新与应用,2016,(08):135.

[2]朱延香, 颜廷财. 侧压式电梯底坑缓冲装置设计 [ J]. 科技资讯,2013,(33):60.

[3] 谢光峰. 探讨电梯安全管理中存在的问题及对策 [J].化工管理,2017,(06):165. 
实现同时的开合且轿门、层门与平层边缘实现精准对接。而 这一动作的精准完成是需要正常运转的门联锁装置进行控 制,这一控制动作是硬件设备和软件设备相互配合完成的。 装置故障可能会导致电梯层门的异常打开或者是轿厢突然 启动,又或者是层门的不启动等。从而造成乘坐者在不留意 的情况在被挤压或者是芏落电梯井等。因此,一方面,在电梯 设计过程中需要增加双重指令判断机制, 这样就相当于是 给电梯门锁增加了一份保险, 从而减少门锁错误开合的可 能性。例如,电梯门锁可以采用电气联动的基础上,增加其他 作用的力来对其进行第二命令,从而保证命令的准确无误。 同时,也可增加逆否命令,例如,在未达到安全位置时,电梯门 执行不打开命令, 和不移动命令, 从而保证电梯内外的乘客 都能得到安全保障。

另一方面, 可以设计一个人体感应装置和故障应急保 护装置。目前的电梯普遍是曳动式的, 受电梯自身特性的限 制,电梯故障为人自身造成的伤害往往是致残,甚至是致命 的。因此,对人生命安全的保护应该是居于第一位的。通过 在电梯轿门、层门等处设置电梯门光幕和热释电人体红外 感应装置,并在系统中建立故障应急保护装置, 可以实现在 电梯发生故障, 造成人体芏落电梯井或是遭到挤压等的情 况下,第一时间感应到人的存在位置,产生相应的有效保护, 避免悲剧的发生。

同时，可以通过在电梯设计过程中增加无线视频监测 工具, 达到对电梯整体甚至是各装置运行状况的实施监督, 并将监测数据进行汇总和评估, 例如, 针对电梯轿层门在层 站非平层区的情况进行精准的检测记录。然后通过评估结 果通知相应的维保单位或个人进行更换或维修。达到实效、 高效的目的。

\section{2 保证电梯产品的生产质量}

电梯的整体结构较为简单, 但是需要各部件的相互配 合, 从而各部件的质量就受到高规格的重视。特别是对于电 梯轿门和层门的安全问题检查。但是在目前的电梯销售市 场上,生产商为了商业利益, 获取买卖合同,往往以低价格作 为销售的卖点。同时为了从中能够获取利润, 只能放弃正规 的零件生产厂家,从而选择一些比较小规模,加工精度等比 较差的小工厂进行生产, 或选用劣质材料从而降低成本, 获 取差价。这样安装的电梯质量与精良的电梯相差甚远, 好比 是一个豆腐渣工程,不管外观多么完美,但确是经不起使用 的。

就好比电梯开关。电梯开关作为电梯运转等命令发出 端口,一般来说, 它的使用频率是相当大的, 因此很轻易就会 坏掉。如果其质量不管是因为材质还是加工, 而没有达到正 规要求, 就很有可能造成失灵或指令错误等, 从而影响电梯 的正常运转,给乘客的安全带来隐患。

另外, 限速器的失灵也会造成电梯的停止动作无法完 成或者是发生偏差,从而造成电梯偏移或掉落等的危险。

3 重视规范电梯日常保养和检修
我国有严格而明确的法律规定, 对于有权从事涉及电 梯安装改造和维修保养等的单位, 要求应具有相关证书, 且 对其工作范围也做出了严格的规定。

但是在利益的驱动下, 形成电梯维保工作不规范, 维保 市场不良竞争激烈的局面, 我国很多从事电梯维护的个人 和企业素质和规模等参差不齐, 由此造成的电梯故障频繁 出现。而一般来说电梯运转是一个各装置之间关联比较大 的机制, 细致且需详加注意的地方比较多, 维保人员需对电 梯的运转, 各零件功能, 各装置连接有清楚专业的认识, 需要 具有认真负责的工作态度,和一丝不苟的从业精神,方才能 给乘客带来比较放心的乘坐体验。就好比对于电梯层门部 分的门锁装置进行检修时, 所应用到的方法和要点就很繁 琐,若是非专业人士或从业素质不具备,很难做到全面细致, 万无一失。

总之, 电梯属于一个五脏俱全的联动装置, 而且各个零 件都有着至关重要的作用。就好比人,任何一部分器官出了 问题,都会产生人自身的不适,影响工作效率。维保工作既要 做中医了解其脉络,调养其身心,也要做中医, 修补其内脏。 而对于电梯轿门和层门部分。该部分是最容易, 也是最先接 触乘客的部分, 维保人员只有按照规定,严格执行相应为安 全装置检修措施,才实现电梯轿门、层门在层站非平层区的 安全保护。

\section{4 加大相关部门的监管力度}

事实上, 从以上论述可以看出, 市场具有其自身特点, 无 论是电梯产品的质量问题还是电梯的日常保养和检修, 都 需要加大相关部门的监管力度,才能得以保证。首先需要,建 立健全相关法律法规。如,根据电梯承载程度等的区别划分, 严格电梯轿门和层门等部分相关装置从材料、型号到规格 的参数执行办法, 并请相关检测机构进行合格率抽查检测, 严格要求生产企业的生产资质、和信誉水平。

同时, 清理目前市场上存在的通过恶性竞争取得维保 资格的个人和单位, 落实责任具体到单位、到个人。注重电 梯日常维护和检修的人员的从业资质和从业水平, 对其进 行定期的专业理论和实践培训、考核、评级和资格审查, 并 制定明文规定,对其工作成绩,或者工作过失按照事情的轻 重程度进行给予相应的奖惩,从而激励其认真工作。对于生 产企业和使用单位, 进行详细明确的事故问责管理办法,规 范其日常管理。

除了职能部门, 媒体部门也应该起到與论监督和與论 引导的作用。及时准确的对市场部存在的不合格产品和恶 性竞争、不负责任的事件进行监督和报道。

\section{5 宣传并正确引导消费者规范使用电梯}

由于电梯的使用目前仍然是一个不断普及的阶段, 人 民群众对其了解很多都还是停留在知之甚少, 逐渐加深的 阶段。特别是在一些拥挤的机场、车站等地方, 人流量比较 大,人员也复杂,携带的行李等较多,因此需要宣传力度的增 加。例如,有些地方安排专人负责电梯的日常乘客情况,这样 


\section{浅析士木建筑基础工程中的 CFG 桩施工要点及其质量控制}

陆炳达

广西建工集团第一建筑工程有限责任公司

DOI:10.18686/bd.v2i2.1227

[摘 要] 基础工程质量直接关系到土木建筑工程安全和稳定,并且其属于地下隐蔽工程,处理比较困难,其合理处理对于建 筑工程项目的顺利实施非常重要,因此为了保障建筑工程的安全性,本文阐述了土木建筑基础工程存在的主要问题以及土 木建筑基础工程 $\mathrm{CFG}$ 桩施工的主要作用,对土木建筑基础工程中的 CFG 桩施工要点及其质量控制进行了探讨分析, 旨在保 障土木建筑工程建设的顺利进行。

[关键词] 土木建筑基础工程; 问题; $\mathrm{CFG}$ 柱施工; 作用; 要点; 质量控制

$\mathrm{CFG}$ 桩是水泥粉煤灰碎石桩的英文简称, 是指以碎石 为基础, 掺人一些石屑、少量水泥和粉煤灰,加水拌合而制成 的桩。土木建筑基础工程中的 CFG 桩施工工艺较为简单, 具有较高的性价比, 能够有效提高土木建筑工程施工质量, 以下就土木建筑基础工程中的 CFG 桩施工要点及其质量 控制进行了探讨分析。

\section{1 土木建筑基础工程存在的主要问题分析}

土木建筑基础工程建设存在的问题主要有:(1) 压缩及 不均匀沉降问题。建筑不可避免的问题是沉降问题,这一直 是专家学者研究的课题之一。当基础在上部结构的自重及 外荷载作用下产生过大变形时, 会影响建筑物的正常使用, 特别是超过规范所容许的不均匀沉降时,结构可能会开裂。 (2)强度及稳定性问题。基础的强度问题直接决定了房建的 质量好坏，当基础的抗剪强度不足以支撑上部结构的自重 及外荷载时,基础就会产生局部或整体剪切破坏。(3)由于动 荷载引起的基础问题。当遇到不可避免的因素,例如地震或 爆破等时,这种动载荷动力会引起基础土、特别是饱和无黏 性土的液化、失稳和震陷等。

\section{2 土木建筑基础工程 CFG 桩施工的主要作用}

土木建筑基础工程 CFG 桩施工的作用主要表现为:(1) $\mathrm{CFG}$ 桩的桩体作用。CFG 桩的桩体压缩性在荷载作用下明 显比其周围的软土小, 因此基础传给复合地基的附加应力 会随着地基的变形而逐渐集中到桩体上, 出现应力明显集
中的现象。由于桩体承受了大部分的荷载,使得桩间土的应 力相应减小, 因此软土地基的承载力比原有地基的承载力 大。此外,地基沉降量减小,伴随着 CFG 桩桩体的刚度增加, 桩体的作用更加明显。(2)裖垫层的作用。裖垫层是由散体材 料组成,主要作用有: 保证桩、土能共同承担荷载; 调整桩的 垂直荷载分担; 减少基础底面应力的集中; 调整桩、土分担 水平荷载的能力。(3)排水作用。土木建筑基础工程中 $\mathrm{CFG}$ 桩施工过程中,当采用沉管灌注施工法时,在施工和成桩后 一段时间内,会不同程度地降低地层中的地下水含量,改善 地基土的物理力学性质。在饱和的粉上、沙土中施工时,沉 管和拔管的振动会让上体产生超孔隙压力, 孔隙水将会沿 着桩体排出,且排出方向向上,直到 $\mathrm{CFG}$ 桩体硬结为止。

3 土木建筑基础工程中的 CFG 桩施工要点及其质量 控制

3.1 土木建筑基础工程中的 CFG 桩施工要点分析。主 要表现为:(1)做好 CFG 桩施工准备。主要表现为:第一、材 料准备。所需材料需检测试验,选定合格的原材料产地或供 应方后, 可进行混合料的配合比试验。第二、合理选用施工 机械。桩机选用需要保证下钻能力,优先选择履带式打桩机, 保证雨期施工,地㬌需优先考虑采用柴油机的,降低施工用 电, 保证桩机使用临水临电保证。第三、技术准备。施工技术 人员熟悉图纸, 现场勘查, 了解场地及周围情况, 编写施工组 织设计, 测设控制点, 并对施工人员进行培训, 对班组进行施

于未然。

参考文献:

[1]张媛.电梯安全隐患的分析及对策探讨 [ J].技术与 市场,2014,(12):991-993.

[2]王建中.电梯失速下降箱内救生装置研究 [J]. 山东 工业技术,2017,(21):220.

[3]罗智菲.电梯人体感应安全保护装置[D].天津大学, 2012,(08):70.

[4]高林林.基于物联网的电梯监控系统设计 [D].中国 科学技术大学,2016,(01):88. 况时有发生。我们应该从多角度考虑,对这一问题进行防患 